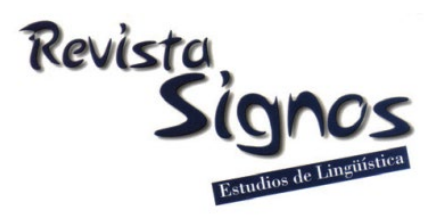

\title{
Marcos predicativos asociados al concepto SIGNO Y SÍNTOMA en textos sobre medicina en español ${ }^{1}$
}

\author{
Predicative frames for the concept SIGN AND SYMPTOM in \\ Spanish Medical Texts
}

\author{
Clara Inés López Rodríguez \\ UNIVERSIDAD DE GRANADA \\ ESPAÑA \\ clarailr@ugr.es
}

Recibido: 05-IV-2018 / Aceptado: 03-VII-2019

DOI: $10.4067 /$ S0718-09342020000200392

\section{Resumen}

En la redacción de textos sobre medicina, una precisa selección de verbos facilita la comprensión de terminología y de las relaciones conceptuales más prototípicas de este dominio. En estudios previos (López Rodríguez, 2007; Buendía, 2013; entre otros) se ha señalado la importancia de estudiar los patrones léxico-sintácticos de verbos en el lenguaje especializado. Con este artículo pretendemos extraer verbos que normalmente coocurren con sintagmas nominales que representan el concepto SIGNO Y SÍNTOMA en textos médicos en español y describir sus patrones combinatorios. Con una metodología de corpus y la plataforma Sketch Engine se ha elaborado un inventario de dichos verbos y se han organizado semánticamente en un esquema de marcos y submarcos, a los que se han asociado plantillas con información semántica y sintáctica sobre las predicaciones verbales que incluyen SIGNO Y SÍNTOMA como argumentos. Los resultados se han aplicado al proyecto de investigación CombiMed (Léxico Combinatorio en Medicina: cognición, texto y contexto) con vistas a la creación de un inventario de base semántica en español para la redacción y traducción de textos médicos.

Palabras Clave: Terminología basada en Marcos, roles semánticos, clasificación semántica de verbos en textos médicos, patrones combinatorios verbales en español, Sketch Engine. 


\begin{abstract}
When writing medical texts, the adequate selection of verbs facilitates the comprehension of the terms and conceptual relations between the most prototypical semantic categories in Medicine. Previous studies (López Rodríguez, 2007; Buendía 2013; inter alia) have emphasized the need to study the lexical and syntactic patterns of verbs in specialized language. The aims of this paper are to retrieve verbs that usually co-occur with noun phrases expressing the concept SIGN AND SYMPTOM in medical texts in Spanish, and to describe their combinatory patterns. A corpus-based methodology and Sketch Engine corpus query system were used to elaborate a repository of those verbs, which have been semantically organized in a schema of frames and subframes. The frames contain templates with semantic and syntactic information about verbal predications where the concept SIGN AND SYMPTOM fits as argument. The results have been relevant for the project CombiMed (Combinatory lexis in Medicine: cognition, text and context) in the proposal of a semantic-based repository of verbs in Spanish for the writing and translation of medical texts.
\end{abstract}

Key Words: Frame-Based Terminology, semantic roles, semantic classification of verbs in medical texts, verb templates in Spanish, Sketch Engine.

\title{
INTRODUCCIÓN
}

Por la supremacía del inglés en la difusión de resultados de investigación, es habitual encontrar, en textos científicos redactados en español (o traducidos del inglés al español), una dependencia terminológica ${ }^{2}$ que hace que los investigadores suelan incorporar, con o sin adaptación, unidades léxicas y estructuras terminológicas completas del inglés "de una manera acrítica, sin cuestionarse su pertinencia y la posibilidad de usar los recursos de su propia lengua" (García Palacios \& Humbley, 2012: 21), así como una "retórica angloamericana" calcada del inglés (Claros, 2016: 11). Parte de esta retórica 'importada' gravita en torno a construcciones verbales que imitan la lengua inglesa. Por ejemplo, autores como Navarro (1997), Rodríguez Medina (2003) o Claros (2016) han señalado que en muchos textos científicos abundan, con más frecuencia de lo habitual en español, los verbos en voz pasiva, el verbo 'poder' (empleado como traducción acrítica de las formas can, could, may y might, que indican en inglés matices de certeza) o verbos copulativos (sobre todo, 'ser'). Por otra parte, el uso de nominalizaciones propio del lenguaje científico (Halliday, 2004; Cademártori, Parodi \& Venegas, 2006) hace que abunden verbos con poca carga semántica ('hacer', 'dar', 'tener', etc.) acompañados de nominalizaciones, cuando existen lexemas verbales para dichas acciones ('cauterizar', 'operar', 'diagnosticar', 'catalizar', 'prescribir', etc.). En este último caso, parece evidente que estudiar verbos léxicos en áreas de conocimiento concretas puede ayudar a profesionales, traductores y redactores técnicos a escribir textos más fluidos.

Este trabajo se centra en verbos que suelen concurrir con sintagmas nominales que expresan el concepto SIGNO Y SÍNTOMA en textos médicos en español para favorecer la comprensión y la redacción de dichos textos. La pertinencia del trabajo se acentúa si 
consideramos que los verbos tradicionalmente no han recibido demasiada atención en los lenguajes especializados salvo excepciones (L'Homme, 1998, 2003; Lorente Casafont, 2002; López Rodríguez, 2007), a pesar de que su significado limita los roles semánticos y las categorías conceptuales de los argumentos con los que se pueden combinar, al tiempo que estos últimos condicionan en cierta manera los verbos que pueden aparecer en su contexto lingüístico. En contexto, dichos verbos adquieren matices de significado asociados a dichos argumentos (Buendía, 2013).

Se pretenden alcanzar dos objetivos: 1) proponer una metodología para recuperar e identificar los verbos que suelen aparecer con términos que denotan SIGNOS y SÍNTOMAS (por ej., 'aliviar', 'apuntar' o 'remitir'), y 2) clasificar semánticamente dichos verbos según los patrones semánticos y sintácticos en los que encajan.

Se combinará el enfoque de la Terminología basada en Marcos (Frame-Based Terminology) de Faber (2012) con las clasificaciones semánticas de la categoría gramatical 'verbo' propuestas desde la Gramática Sistémico-Funcional de Halliday (Halliday \& Matthiessen, 2004), la Gramática Léxica de Faber y Mairal (1999) y el proyecto ADESSE (Albertuz, 2007), siempre destacando la naturaleza composicional del léxico. La Terminología basada en Marcos (TbM) es una aproximación cognitiva para la representación del conocimiento especializado y la gestión terminológica que sigue presupuestos de la Semántica de Marcos (Lehrer \& Kittay, 1992; Fillmore \& Atkins, 1992) y la Cognición Situada de Barsalou (2008). La TbM se ha aplicado con éxito en investigaciones sobre la terminología y las características del lenguaje de especialidad en diferentes lenguas y ámbitos como la medicina (OncoTerm, 2002; Tercedor, López \& Prieto, 2014; Jiménez \& Tercedor, 2017) y las ciencias ambientales (EcoLexicon: [http://ecolexicon.ugr.es]). Los trabajos sobre verbos llevados a cabo dentro de la TbM (López Rodríguez, 2007, 2016; Buendía, 2013; Buendía, León \& Sánchez, 2016) servirán de punto de partida para el diseño de la metodología de este artículo (apartado 2), aunque previamente en el apartado 1 revisamos teorías sobre los patrones sintácticos y semánticos de la predicación verbal en lengua española.

\section{Marco teórico}

\subsection{Los signos y síntomas en contexto: Escenas y marcos}

Según la Semántica de Marcos (Frame Semantics), el significado de las palabras se entiende en función de un conjunto de experiencias, creencias y prácticas que conocen y comparten los hablantes de una lengua (Fillmore \& Atkins, 1992). El sentido de las palabras no surge simplemente de las relaciones entre ellas, sino a partir de 'marcos' de conocimiento compartido almacenados en la mente de los hablantes en forma de representación esquemática. Los marcos son configuraciones dinámicas, flexibles y sensibles al contexto, se construyen y actualizan continuamente (Barsalou, 1992) y pueden ser muy generales ('escenas') o bien más concretos y de carácter lingüístico ('marcos'). Fillmore (1977: 63) define 'escena' de este modo: 
"not only visual scenes, but also familiar kinds of interpersonal transactions, standard scenarios, familiar layouts, institutional structures, enactive experiences, body image; and in general, any kind of coherent segment, large or small, of human beliefs, actions, experiences, or imaginings".

Según este autor, al aprender una lengua, asociamos estas escenas con 'marcos', de carácter lingüístico, que comprenden: "any system of linguistic choice -the easiest being collections of words, but also including choices of grammatical rules o grammatical categories - that can get associated with prototypical instances of scenes" (Fillmore, 1977: 63). Y lo ilustra con la escena 'escribir correspondencia', que se lexicaliza en inglés con el verbo to write y una serie de participantes (el remitente, un utensilio de escritura, un papel, un destinatario, etc.) y relaciones conceptuales entre estos elementos.

Un aspecto de la Semántica de Marcos, que se reflejará en los resultados del presente artículo, es que sostiene que cada marco focaliza una perspectiva diferente. Y así, las predicaciones prototípicas disponibles en inglés para una escena de 'transacción comercial' gravitan en torno a los verbos buy, sell, charge, cost y pay, y cada uno de ellos destaca un aspecto concreto de esa escena, ya sean los participantes o las relaciones conceptuales entre ellos. Los participantes de la predicación se denominan frame elements en la aplicación práctica de la Semántica de Marcos: el proyecto FrameNet. En la Figura 1, se muestra cómo FrameNet describe el marco CONDITION_SYMPTOMRELATION (RELACIÓN ENTRE ENFERMEDAD Y SÍNTOMAS), en el que los elementos imprescindibles (Core Frame Elements) son PACIENTE, ENFERMEDAD y SÍNTOMA, que funcionan como argumentos de verbos como manifest o present.

Definition: A Patient has a Medical_condition that can be understood by its Symptoms. This frame has been constructed to list all the ways to speak of relating a Patient, a Medical_condition, and Symptoms, including LUs that are also related to much more general frames like Causation (e.g. cause.v). [...]

\section{Tietze Syndrome and Costochondritise MANIFESTED by painful swelling of one or more costochondral articulations}

\section{Core Frame elements (FEs):}

\begin{tabular}{|c|c|}
\hline $\begin{array}{l}\text { Medical__ } \\
\text { condition [] }\end{array}$ & $\begin{array}{l}\text { A holistic description of the medical state of the Patient (or a part of the state of } \\
\text { the Patient), which may or may not indicate the cause of a deviation from normal. }\end{array}$ \\
\hline Patient [] & $\begin{array}{l}\text { The person who has a Medical_condition associated with Symptom. } \\
\text { Premenopausal women often will PRESENT with atypical bleeding between typical } \\
\text { menstrual cycles. }\end{array}$ \\
\hline Symptom [] & $\begin{array}{l}\text { A deviation from normal function or feeling which is noticed by a Patient or physician, } \\
\text { indicating the presence of a Medical_condition }\end{array}$ \\
\hline
\end{tabular}

Figura 1. Versión resumida del marco CONDITION_SYMPTOM-RELATION de FrameNet https://framenet2.icsi.berkeley.edu/fnReports/data/frameIndex.xml?frame=Condition_sy mptom_relation 
En esta misma línea, la Terminología basada en Marcos (TbM) destaca la relevancia del contexto lingüístico, profesional y comunicativo en la construcción del conocimiento experto, que se codifica en la lengua y en los textos (Faber, 2012). A partir de la TbM es posible identificar la organización conceptual subyacente a dichos campos del saber y representarla en forma de dominios léxicos (lexical domains), marcos (frames) y patrones definicionales (definitional templates). Para ello, se extrae el conocimiento codificado en el léxico de dichos campos mediante el análisis de corpus comparables, la consulta de diccionarios y bases de datos terminológicas y la colaboración con expertos. En sus orígenes, la TbM desarrolló una base de conocimiento sobre el cáncer denominada OncoTerm [http://www.ugr.es/ oncoterm] y estudió los conceptos y relaciones prototípicas de la Oncología, sistematizados en un marco general de conocimiento denominado el Evento Médico (Faber, 1999) que vinculaba diferentes categorías conceptuales propias de la Oncología: SÍNTOMA, FÁRMACO, EFECTO SECUNDARIO, FACTOR DE RIESGO, PROCEDIMIENTO DIAGNÓSTICO, PARTE DEL CUERPO, TUMOR, INSTRUMENTO, TRATAMIENTO, ESPECIALISTA y HOSPITAL (Onco'Term, 2002).

Finalmente, para estudiar los marcos prototípicos en torno a la escena UNA PERSONA TIENE SIGNOS Y SÍNTOMAS, PROBABLEMENTE ASOCIADOS A UNA ENFERMEDAD, es necesario conocer dónde encajan los conceptos SIGNOS y SÍNTOMAS en el contexto de la medicina y las ciencias de la salud. El Diccionario médicobiológico, bistórico y etimológico (Cortés Gabaudan, 2007) define 'signo' como la 'manifestación objetiva de una enfermedad o estado que el médico percibe o provoca', mientras que 'síntoma' es la 'manifestación subjetiva de una enfermedad, apreciable solamente por el paciente, como el dolor, picor, visión de 'moscas volantes', etc.'. En los Descriptores en ciencias de la salud [http://decs.bvsalud.org/E/homepagee.htm], traducción de las entradas del tesauro MeSH de la National Library of Medicine de los Estados Unidos, existe la categoría 'Signos y síntomas' (C23.888), definida como 'manifestaciones clínicas que pueden ser, o bien objetivas cuando son observadas por el médico, o subjetivas cuando son percibidas por el paciente'.

Aunque SIGNO y SÍNTOMA son conceptos diferentes, dado que coexisten en el diagnóstico y sus límites no son siempre precisos, el hablante medio y muchas obras divulgativas sobre medicina suelen agruparlos bajo un mismo concepto SIGNO Y SíNTOMA, y así se hará en este artículo. Una vez definidos estos conceptos, revisaremos algunas nociones sobre la predicación verbal, que servirán de base para indagar cómo las lexicalizaciones de SIGNO y SÍNTOMA encajan en marcos predicativos.

\subsection{Elementos sintácticos y semánticos de la predicación verbal}

Los verbos son el elemento nuclear de las predicaciones y proposiciones sobre las que se construye un texto. En una predicación, normalmente hay un verbo que, según 
su significado, tiene el potencial de completar dicho significado con una serie de expresiones (actantes o argumentos), que ocuparán en la oración las posiciones permitidas por la gramática de una lengua concreta. Esta vinculación entre los verbos y otros elementos que componen la predicación está presente en diferentes clasificaciones de los verbos y predicados en función de su valencia, en trabajos sobre roles y macrorroles semánticos y en clasificaciones semánticas de verbos.

\subsubsection{La valencia verbal y los argumentos de una predicación}

Desde que Tesnière (1959) propusiera la noción de 'valencia verbal', inspirándose en las valencias de los elementos químicos, muchos autores la han aplicado a estudios sintácticos y semánticos del verbo (Fillmore \& Atkins, 1992; Lezcano, 1994/1995; Escandell, 2004, entre otros). El concepto de 'valencia' hace referencia al número de expresiones, denominadas argumentos, con las que un predicado debe combinarse para poder quedar completo.

En español, Escandell (2004), siguiendo a Tesnière (1959), clasifica los predicados según su valencia en 4 tipos: a) predicados de valencia 0 , que no requieren ningún argumento (verbos meteorológicos o impersonales); b) los de valencia 1, que requieren un argumento que tiene la función sintáctica de sujeto de un verbo intransitivo; c) predicados de verbos transitivos que necesitan dos argumentos (valencia 2); y d) predicados de valencia 3, que requieren tres argumentos (predicados ditransitivos).

Al describir la valencia verbal, solo se considera el número de expresiones necesarias para completar el significado del verbo, a las que Tesnière (1959) denomina actants. Según este autor, en torno al verbo se configuran elementos que pueden funcionar como actants (sujeto, complemento directo, complemento indirecto) y otros opcionales que le aportan contenido adicional, a los que llama circonstants (Allerton, 1982, citado en Lezcano (1994). La distinción entre 'actantes' y 'circunstantes' es similar a la de ‘argumentos’ y 'satélites' de la Gramática Funcional de Dik (1989).

La noción de valencia, aunque entendida en un sentido más amplio, es fundamental en proyectos de investigación como FrameNet (véase apartado 1.1), en el que la valencia o estructura argumental de las palabras comprende los elementos semánticos (roles semánticos) y sintácticos (número de argumentos) que necesita esa palabra para usarse en contexto (Fillmore \& Atkins, 1992). En el presente artículo, la noción 'valencia' hace referencia al número de argumentos con los que debe combinarse un verbo para completar su significado. Relacionaremos la valencia de un verbo con los roles semánticos y función sintáctica de sus argumentos. 


\subsubsection{Macrorroles semánticos, roles temáticos y semánticos de los argumentos}

La asignación de roles semánticos, también conocidos como roles temáticos, supone relacionar el plano semántico y sintáctico de la lengua. Como ha sido difícil precisar cuáles y cuántos roles semánticos existen (Dowty, 1991; Reisinger, Rudinger, Ferraro, Harman, Rawlins \& Van Durme, 2015), para facilitar el encaje de los roles en la sintaxis, se han propuesto dos grandes roles semánticos que agruparían a los demás.

Dowty (1991) propone dos roles prototípicos (proto-agent y proto-patient) aplicando la teoría de prototipos (Rosch \& Mervis, 1975). Un argumento puede ser más agente o más paciente según cumpla un mayor número de propiedades inherentes al rol de 'proto-agente' o 'proto-paciente'. ${ }^{3}$

De forma parecida, Van Valin (2004) identifica dos 'macrorroles semánticos' (ACTOR y UNDERGOER) que engloban a los roles que pueden desempeñar los argumentos según la estructura lógica del verbo con el que se combinan. Y ordena los roles semánticos en un gradiente, de forma que Agent sería el que más representa el macrorrol de ACTOR, y Patient, el de UNDERGOER: 'Agent $>$ Effector $>$ Experiencer $>$ Location $>$ Theme $>$ Patient'. Posteriormente, Van Valin (2004) organiza los roles semánticos en tres niveles, de más específico a más general: a) 'roles semánticos' inherentes al verbo en cuestión (giver, runner, killer, speaker, dancer, hearer, located, broken...); b) 'relaciones temáticas', que son generalizaciones sobre los roles anteriores: agent, experiencer (cognizer, perceiver, emoter), recipient, stimulus, theme patient, y c) 'macrorroles semánticos', que generalizan sobre las relaciones temáticas: Actor (para englobar agent, experiencer y recipient) y Undergoer (experiencer, recipient, stimulus, theme y patient).

En el apartado 2.2 se utilizarán, por una parte, los roles prototípicos de 'Agente' y 'Paciente' para filtrar las concordancias y elaborar marcos conceptuales, y por otra, roles semánticos específicos de los verbos identificados.

\subsubsection{Hacia una clasificación semántica de los verbos en español}

Siguiendo a Demonte (1990), en la Gramática descriptiva de la lengua española (Bosque \& Demonte, 1999), se dividen los verbos transitivos en dos grandes superclases: 1) verbos en los que el sujeto es agente o causa y el complemento directo, paciente; ${ }^{4}$ y 2 ) verbos de actividad cognitiva, que van acompañados de un 'experimentante', es decir, un actor involucrado y afectado por la acción del verbo. ${ }^{5}$ En esta misma obra, los verbos intransitivos se diferencian semánticamente en dos grandes tipos: 1) verbos inergativos, que denotan actividades o procesos que dependen de la voluntad de un agente ('toser' o 'saltar'); y 2) verbos inacusativos, que indican estados o eventos no agentivos (logros) cuyo único argumento es el elemento que recibe la acción o en el que se produce o manifiesta la eventualidad que denota el verbo ('existir', 'florecer' o 'llegar'). 
Por otra parte, la Nueva gramática de la lengua española (Real Academia Española y Asociación de Academias de la Lengua Española, 2009) aborda la semántica de los verbos principalmente en relación con el 'aspecto léxico' y para clasificar las perífrasis verbales. El aspecto léxico ${ }^{6}$ es una propiedad temporal de los predicados (no solo de los verbos) que permite describirlos según exista un "final o límite natural o intrínseco de las acciones y los procesos que se expresan" (RAE y ASALE, 2009: 1686). Esta gramática clasifica el aspecto léxico conforme a las categorías de Vendler (1967): activity (actividad), accomplishment (realización o efectuación), achievement (consecución y logro) y state (estado). Como el aspecto léxico obedece a rasgos semánticos de carácter temporal (duración, delimitación/telicidad y dinamismo), resulta insuficiente para articular una clasificación semántica de los verbos en español, de ahí que, a continuación, revisemos clasificaciones semánticas adicionales de los verbos.

La Gramática Sistémico-Funcional (Halliday \& Matthiessen, 2004) explica la interfaz semántico-sintáctica de las predicaciones mediante los sistemas de la transitividad y de la agentividad. El 'sistema de la transitividad' interpreta nuestra experiencia del mundo en función de tipos de procesos que representan, a grandes rasgos, las nociones de SER, HACER y SENTIR (Halliday \& Matthiessen, 2004). Y así, existen: a) PROCESOS MATERIALES (procesos de nuestra experiencia exterior), que son los que pensamos que ocurren fuera de nosotros; b) PROCESOS MENTALES como la percepción, la emoción y la imaginación, que ocurren dentro de nuestra conciencia (procesos de nuestra experiencia interior); y c) PROCESOS RELACIONALES, que permiten identificar y clasificar la experiencia. Entre estas categorías, existen categorías intermedias. Entre los procesos materiales y los mentales están los COMPORTAMENTALES (manifestaciones externas de procesos internos como 'dormir' o 'reír'). Entre los mentales y los relacionales se encuentran los VERBALES, y entre los relacionales y los materiales, habría un tipo de procesos EXISTENCIALES. Cada predicación tiene asociada unos participantes, que se expresan mediante sintagmas nominales con roles semánticos definidos en el 'sistema de la agentividad'. Por ejemplo, en un proceso mental, hay un participante central, normalmente dotado de conciencia, que tiene el papel semántico de senser, y un participante secundario con el papel de phenomenon. Si se trata de un proceso existencial, lo habitual es que haya un solo participante con el papel de Existent.

La Gramática Léxica de Faber y Mairal (1999), tras aplicar un método inductivo basado en el Modelo Lexemático Funcional de Martín Mingorance (1984, 1990, 1995), representa la arquitectura del lexicón verbal en lengua inglesa con un inventario de dominios léxicos (Tabla 1). 
Tabla 1. Inventario de dominios léxicos y algunos verbos prototípicos (Faber \& Mairal, 1999).

1.EXISTENCE (exist, be, happen, live)

2. Movement (go, move, come)

3. Position (be, stay, put, lie)

4. CONTACT (hit)

5. CHANGE (become, change)

6. PerCeption (perceive, notice, find, discover, see,

hear, taste, smell, touch)

7. COGNITION (know, think about)
8. FEELING (feel, suffer, enjoy, grieve, love, want, wish)

9. SPEECH (say, speak, talk)

10. Sound (shout, cry, laugh, cough)

11. LiGHT (shine, darken)

12. POSSESION (have/give)

13. ACTION (do, make, perform)

Finalmente, destacamos la clasificación de verbos en español del proyecto ADESSE (Alternancias de Diátesis y Esquemas Sintáctico-Semánticos del Español), que se inspira en la Gramática de Construcciones de Goldberg (1995, citado en García-Miguel, 2005). Contiene seis categorías generales muy parecidas a las propuestas por Halliday y Matthiesen (2004), aunque en ADESSE [http://adesse.uvigo.es/] se llega a un nivel de detalle encomiable, que se fundamenta en el análisis de un corpus etiquetado y en criterios semánticos ${ }^{7}$ y sintácticos (Tabla 2). En el proyecto se han etiquetado sintáctica y semánticamente los verbos y argumentos de los textos contemporáneos del corpus del español Arthus conforme a las categorías de la Base de Datos Sintácticos del Español Actual. Se parte de la premisa de que los significados se construyen dinámicamente en contexto integrando significado verbal y significado construccional, de ahí que el marco conceptual que proporciona el verbo con su esquema sintáctico resulte modificado, tanto por los elementos léxicos que se combinan con él, como por el esquema construccional en el que encajan en contexto (García-Miguel, 2005). Es decir, el verbo adquiere un protagonismo similar al de los elementos léxicos con los que se combina. De hecho, en ADESSE se asocian roles semánticos [http://adesse.uvigo.es/index.php/Docu/Roles] y posiciones según la clase de verbo. 
Tabla 2. Clases y subclases semánticas del proyecto ADESSE [http://adesse.uvigo.es/data/clases.php]

\begin{tabular}{|c|c|c|}
\hline Macroclase & Clase & Subclase \\
\hline \multirow[t]{4}{*}{ MENTAL } & Sensación & Volición \\
\hline & Percepción & \\
\hline & Cognición & Conocimiento, Creencia \\
\hline & Elección & \\
\hline \multirow[t]{2}{*}{ RELACIONAL } & Atribución & $\begin{array}{l}\text { Relación, Propiedad (Medida y Apariencia), } \\
\text { Denominación, Cambio de estado }\end{array}$ \\
\hline & Posesión & Adquisición, Transferencia \\
\hline \multirow[t]{4}{*}{ MATERIAL } & Espacio & $\begin{array}{l}\text { Desplazamiento, Localización, Postura-posición, Orientación, } \\
\text { Manera movimiento, Unión }\end{array}$ \\
\hline & Cambio & $\begin{array}{l}\text { Creación, Modificación (Cuidado corporal), } \\
\text { Destrucción }\end{array}$ \\
\hline & Otros hechos & $\begin{array}{l}\text { Meteorología, Emisión, Contacto (contacto simple, impacto, } \\
\text { presión, fricción, contacto afectivo), Control, Uso (Consumo), } \\
\text { Sustitución, Actividad, Competición }\end{array}$ \\
\hline & Comportamiento & Fisiología (Ingestión), Relaciones sociales \\
\hline \multirow[t]{3}{*}{ VERBAL } & Comunicación & Petición \\
\hline & Valoración & \\
\hline & Emisión de sonido & \\
\hline \multirow[t]{3}{*}{ EXISTENCIAL } & Existencia & \\
\hline & Fase-Tiempo & Fase, Tiempo \\
\hline & Vida & \\
\hline \multirow[t]{4}{*}{ MODULACIÓN } & Causación & Inducción, Permiso, Obligación \\
\hline & Disposición & \\
\hline & Aceptación & \\
\hline & Verb. de apoyo & \\
\hline
\end{tabular}

Aunque el proyecto ADESSE estudie los verbos en la lengua general, ha servido para el presente trabajo, dado que su base de datos permite búsquedas avanzadas de gran precisión o recuperar las diferentes acepciones del verbo, su clase semántica y el rol semántico de los argumentos que requiere.

\section{Metodología}

La metodología de este artículo persigue identificar, en textos sobre medicina en español, predicaciones que incluyen como argumentos sintagmas nominales que denotan la categoría conceptual SIGNO Y SÍNTOMA, así como extraer los verbos más prototípicos de dichas predicaciones y representarlos en un marco de conocimiento. Dicho marco se relaciona con el esquema, destinado a un público no experto en medicina, elaborado por la autora de este artículo para el proyecto CombiMed y publicado en la pestaña Fraseología de su diccionario médico asociado: VariMed [http://varimed.ugr.es]. Desde esta pestaña se pueden consultar en abierto fichas fraseológicas con verbos y contextos de uso extraídos de corpus correspondientes a las categorías SIGNO Y SÍNTOMA y ENFERMEDADES (Figura 2). 
consulta de verbos

Verbos y contextos de uso relacionados con

- SIgNOS Y SínTOMAS

- ENFERMEDAD

- proceso que se inicia, se desarrolla y/o afecta a las personas

- prevención de la enfermedad

- factores de riesgo

causas de la enfermedad

contagio de la enfermedad

tener la enfermedad

diagnóstico de la enfermedad

tratamiento y lucha contra la enfermedad

- curación de la enfermedad

Figura 2. Esquema general para la descarga de fichas fraseológicas (proyecto CombiMed).

Se han seguido técnicas de análisis de corpus, otorgando un mayor peso a los aspectos cualitativos que a los cuantitativos, ya que se pretendía estudiar desde un punto de vista semántico y sintáctico el mayor número de variantes léxicas de verbos que concurren con SIGNOS Y SÍNTOMAS en marcos predicativos concretos, y no tanto los lexemas verbales más frecuentes, que suelen ser palabras de la lengua general (por ejemplo, 'ser', 'aparecer', 'tener' o 'aliviar'). Sketch Engine (Lexical Computing, s. f.) ha sido la herramienta empleada en la compilación y en el análisis de corpus.

Por otra parte, en la sistematización de los marcos de conocimiento han sido de utilidad la base de datos de ADESSE, el asesoramiento y revisión de Antonio Jesús Laínez Ramos-Bossini (Licenciado en Medicina y en Traducción e Interpretación) y el análisis de Buendía (2013) de la fraseología de la combinación 'verbo y sintagma nominal' en ciencias ambientales. Asimismo, hemos extrapolado a nuestro estudio monolingüe esta hipótesis de Buendía et al. (2016: 66):

"los verbos equivalentes en distintas lenguas próximas comparten una misma estructura actancial [...], es decir, sus argumentos tienen el mismo rol semántico y función sintáctica [...] y los términos que actúan como argumentos pertenecen a una misma clase conceptual".

\subsection{Descripción de los corpus}

Los corpus analizados se detallan en la Tabla 3. Para anotarlos morfológicamente, en la plataforma Sketch Engine, se seleccionaron las etiquetas de FreeLing. ${ }^{8}$ Los diferentes componentes del corpus, que incluyen textos sobre medicina de niveles diferentes de especialización, no fueron suficientes para encontrar algunos verbos que sugería el experto en medicina, de ahí que puntualmente se recurriera al corpus EsTenTen11 de Sketch Engine e incluso al buscador Google. 
Tabla 3. Datos sobre los corpus utilizados.

\begin{tabular}{|l|l|l|l|}
\hline \multicolumn{1}{|c|}{ Corpus español } & \multicolumn{1}{|c|}{ Contenido } & \multicolumn{1}{|c|}{ Destinatarios } & \multicolumn{1}{c|}{ Palabras } \\
\hline Medicina Clínica & Artículos de investigación & Experto & 690.460 \\
\hline $\begin{array}{l}\text { Investigación y } \\
\text { Ciencia_Medicina }\end{array}$ & Divulgación semi-especializada. Medicina & Semi-experto & 324.519 \\
\hline Libro de la Salud & Capítulos sobre aspectos claves en salud & Lego & 403.985 \\
\hline EASP & $\begin{array}{l}\text { Folletos de la Escuela Andaluza de Salud } \\
\text { Pública }\end{array}$ & Lego & 134.699 \\
\hline Cardiovascular & $\begin{array}{l}\text { Divulgación sobre enfermedades } \\
\text { cardiovasculares }\end{array}$ & Lego & 1.111 .053 \\
\hline Oncoterm_es & $\begin{array}{l}\text { Textos en epañol sobre cancer del proyecto } \\
\text { Oncoterm }\end{array}$ & $\begin{array}{l}\text { Experto, semi- } \\
\text { experto y lego }\end{array}$ & 13.643 .317 \\
\hline EseuTenTen & $\begin{array}{l}\text { Textos de lengua general en español de } \\
\text { España (dominio .es) } \\
\text { [Sección del EsTenTen11] }\end{array}$ & Lego & 2.021 .756 .831 \\
\hline
\end{tabular}

\subsection{Protocolo de extracción de ejemplos, clasificación y análisis}

De cara a obtener ejemplos del corpus y para posteriormente cribarlos y extraer patrones semánticos y sintácticos en torno a los verbos, se siguieron estos pasos:

1) Se buscaron en diccionarios y nomenclaturas médicas lexicalizaciones para el concepto SIGNO Y SÍNTOMA, así como hipónimos (dolor, picor, disnea...) destacados en portales médicos como Onmeda, ${ }^{9}$ y se combinaron con los conceptos categorizados en la base de datos de CombiMed como tipo de SIGNO/SÍNTOMA que afecta a todo el cuerpo: http://combimed.ugr.es/combimed/search.php?

2) Con Sketch Engine, se generaron word sketches para los lemas 'signo', 'síntoma', 'indicio', 'señal', 'dolor', 'disfunción', 'fiebre', 'picor', 'disnea' y 'tos'. De estos word sketches se seleccionaron los patrones subject_of para verbos cuyo sujeto era uno de estos lemas, y object_of para los que llevan dichos lemas como complemento directo. Se consultaron las concordancias asociadas y se constató que, en muchos casos, cuando el verbo aparece después de un sintagma nominal, el sujeto tiene el macrorrol semántico de Agente, aunque en español también resulta habitual encontrar sujetos pospuestos al verbo o incluso complementos directos antepuestos al verbo en subordinadas de relativo: '...los síntomas que el médico advierte en su relación con el enfermo'. En el patrón verbs with 'sintoma' as subject, algunos verbos como 'soler' o 'poder' proporcionaron resultados adicionales.

3) En una hoja de cálculo, se anotaron los verbos, sus frecuencias relativas y si las diferentes lexicalizaciones de SIGNO Y SÍNTOMA funcionaban como argumento 1 (sujeto), argumento 2 o 3 (complementos directo, indirecto, de régimen verbal o complemento predicativo) o como satélite (complemento circunstancial). Se consideró pertinente incrementar el inventario de verbos, esta vez con la sintaxis de búsqueda acotada del Corpus Query Language. 
4) Se exploró la sintaxis de búsqueda (Corpus Query Language) que podría arrojar los mejores resultados para patrones verbales concretos en cuanto a exactitud y cantidad de resultados que plasmaran la variedad léxica de verbos (Figura 3). Por ejemplo, la etiqueta morfológica $V M$ de Freeling indica un verbo principal o $D$, un determinante. Es posible especificar la distancia en palabras entre los elementos buscados, de forma que $\square\{0,2\}$ abre la posibilidad de que existan entre 0 y 2 palabras de separación entre ellos.

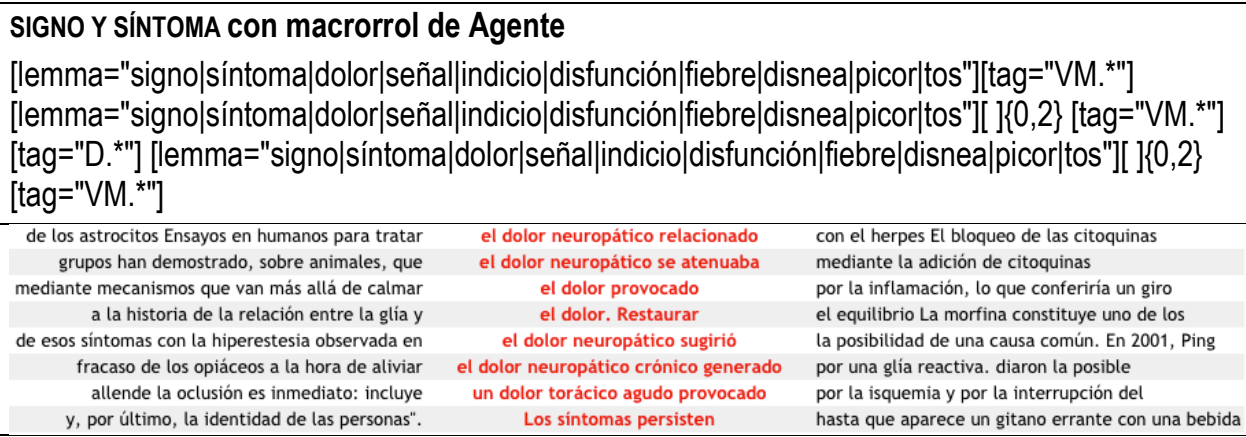

el dolor neuropático relacionado el dolor neuropático se atenuaba el dolor provocado el dolor. Restaurar

el dolor neuropático sugirió

el dolor neuropático crónico generado un dolor torácico agudo provocado Los sintomas persisten

con el herpes El bloqueo de las citoquinas mediante la adición de citoquinas por la inflamación, lo que conferiría un giro el equilibrio La morfina constituye uno de los la posibilidad de una causa común. En 2001, Ping por una glía reactiva. diaron la posible por la isquemia y por la interrupción del hasta que aparece un gitano errante con una bebida

\section{SIGNO Y SÍNTOMA con macrorrol de Paciente}

[tag="VM.*"] [lemma="signo|síntoma|dolor|señal|indicio|disfunción|fiebre|disnea|picor|tos"] [tag="VM. *"][ ]\{0,1\}[lemma="signo|síntoma|dolor|señal|indicio|disfunción|fiebre|disnea|picor|tos"]

y el 15 por ciento de las caucásicas están magnética funcional, técnicas inocuas, no

del estrés. $Y$ es posible que ayude al cuerpo a numerosos obstáculos: en los pacientes que aún no ensayarse esos biomarcadores en personas que no punto consistiría en empezar con pacientes que exp Innovadoras (CSCTI)- es un refugio para quienes

la sangre se estanca. Las varices graves pueden en un determinado órgano para que éste empiece a presentando signos captaban signos

sentir dolor

presentan sintomas

presentaran sintomas

xperimentaran sintomas

presentan síntomas

causar dolor

mostrar síntomas puberales, sobre todo en el desarrollo de las de actividad basal en el cerebro cuando el , para que reaccione en consecuencia. Por otra , resulta difícil valorar los posibles - La mejor manera de llegar a ese punto consistiría recientes, y a partir de ahí, ir retrocediendo de alteración de la memoria, que en ocasiones e inflamaciones y, en raras ocasiones, coágulos de enfermedad? Y si priorizamos la actuación en

Figura 3. Ejemplos de sintaxis de búsqueda para recuperar concordancias en Sketch Engine.

5) Se propuso una formulación preliminar de escena, marcos y submarcos, con el asesoramiento del médico y se registraron contextos de uso ilustrativos, que publicamos en el diccionario VariMed [http://varimed.ugr.es/archivo/signos_sintomas.pdf] como recurso fraseológico para traductores, redactores técnicos y público general.

6) Se elaboraron fichas descriptivas con la siguiente información semántica y sintáctica: a) Clase y subclase semántica de los verbos según ADESSE; b) Valencia; c) Concepto que en la predicación tiene la función de sujeto y su rol semántico; d) Verbos que encajan en esa clase y en ese patrón combinatorio; y e) Conceptos para argumentos que no tienen la función de sujeto, su rol semántico y su función (complemento directo, complemento indirecto, complemento de régimen verbal o complemento predicativo). Cuando existían circunstantes o satélites del verbo, se 
especificó en tabla aparte y estos no computaron para la descripción de la valencia verbal.

7) Se revisaron los patrones sintácticos y semánticos de los verbos de los marcos y se formuló una propuesta final, que mostramos a continuación.

\section{Resultados y discusión}

Tras el análisis de patrones y líneas de concordancia y la consulta al experto médico, se ha propuesto un esquema con siete marcos diferentes para la escena UNA PERSONA TIENE SIGNOS Y SÍNTOMAS, PROBABLEMENTE ASOCIADOS A UNA ENFERMEDAD (Tabla 4). Refleja las predicaciones y categorías conceptuales 'activadas' en este contexto y sus posiciones en la estructura argumental. Se han seleccionado verbos frecuentes que estaban presentes en todos los subcorpus, recuperados con las fórmulas de búsqueda descritas en el apartado 2.2.

Tabla 4. Marcos y submarcos de las predicaciones verbales que incluyen SIGNO Y SÍNTOMA como argumentos.

\begin{tabular}{|c|c|c|}
\hline \multicolumn{3}{|c|}{ A. SIGNOS/SÍNTOMAS EN EL PACIENTE } \\
\hline \multicolumn{3}{|c|}{ 1. Aparición y existencia de signos/síntomas } \\
\hline SIGNO/SÍNTOMA & $\begin{array}{l}<\text { aparece }>,<\text { aumenta }>, \\
<\text { disminuye }>,<\text { empeora }>\text {, } \\
<\text { dura }> \\
<\text { desaparece }>\end{array}$ & $\begin{array}{l}- \\
- \\
\text { TIEMPO } \\
-\end{array}$ \\
\hline \multicolumn{3}{|c|}{ 2. Tener, percibir y sentir signos/síntomas } \\
\hline PACIENTE & $\begin{array}{l}<\text { tiene }>,<\text { percibe }>, \\
<\text { experimenta }>,<\text { tolera }> \\
<\text { permanece asintomático }>\end{array}$ & $\begin{array}{l}\text { SIGNO/SÍNTOMA } \\
-\end{array}$ \\
\hline SIGNO/SÍNTOMA & $<$ molesta $>$ & PACIENTE \\
\hline \multicolumn{3}{|c|}{ 3. Signos/síntomas relacionados con la enfermedad } \\
\hline SIGNO/SÍNTOMA & $<$ se asocia $>$ & a ENFERMEDAD \\
\hline ENFERMEDAD & $<$ cursa $>$ & con SIGNO/SÍNTOMA \\
\hline \multicolumn{3}{|c|}{ 4. La enfermedad causa signos/síntomas } \\
\hline ENFERMEDAD & $<$ causa $>$ & SIGNO/SÍNTOMA \\
\hline \multicolumn{3}{|c|}{ B. SIGNOS y SÍNTOMAS EN UN ENTORNO MÉDICO } \\
\hline \multicolumn{3}{|c|}{ 5. Signos y síntomas en el diagnóstico de la enfermedad } \\
\hline PACIENTE & $<$ describe $>,<$ experimenta $>$ & SÍNTOMA \\
\hline PROFESIONAL SANITARIO & $<$ halla $>$ & SIGNO \\
\hline SIGNO Y SÍNTOMA & $<$ indica $>,<$ descarta $>$ & ENFERMEDAD \\
\hline \multicolumn{3}{|c|}{ 6. Prevención y control de signos y síntomas } \\
\hline PROFESIONAL SANITARIO & $<$ vigila $>$ & \\
\hline TRATAMIENTO & $<$ previene $>,<$ controla $>$ & SIGNO Y SÍNTOMA \\
\hline \multicolumn{3}{|c|}{ 7. Alivio de síntomas (tratamiento sintomático) } \\
\hline $\begin{array}{l}\text { TRATAMIENTO, HÁBITO } \\
\text { SALUDABLE, ALIMENTACIÓN }\end{array}$ & $\begin{array}{l}<\text { alivia }>,<\text { detiene }> \\
<\text { suprime }>\end{array}$ & SÍNTOMA \\
\hline
\end{tabular}

En la tabla se ha establecido una distinción entre los SIGNOS Y SÍNTOMAS conceptualizados con independencia de un entorno sanitario (que se desglosarán en los subapartados 3.1 a 3.4), y cuando estos son hallazgos clínicos en un entorno con 
profesionales de la salud (de 3.5 a 3.7). Los contextos de uso más representativos para cada marco están publicados en un archivo pdf disponible desde el diccionario VariMed [http://varimed.ugr.es/archivo/signos_sintomas.pdf], donde se presentan estos patrones y todos los verbos encontrados en el análisis, junto con oraciones donde se destaca el verbo en negrita. Muchos de los verbos más prototípicos recuperados a partir de los word sketches y las fórmulas de búsqueda eran muy generales (Figura 4), por lo que en los siguientes apartados se incluirán también verbos adicionales, menos frecuentes pero más especializados, hallados en textos para público experto o semi-experto.

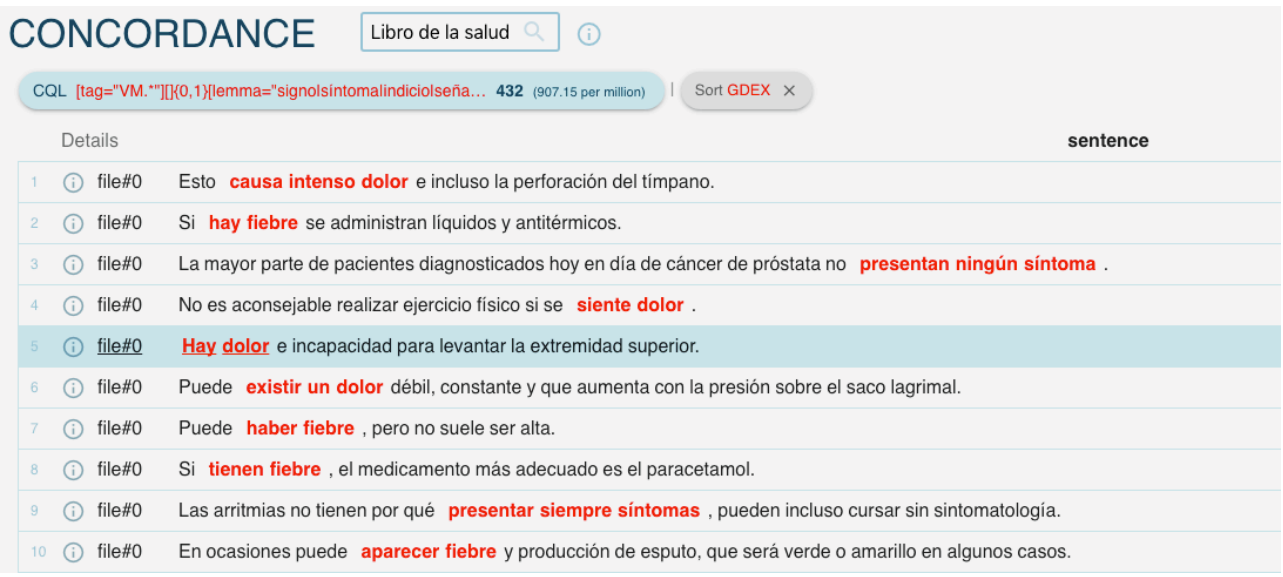

Figura 4. Ejemplos del subcorpus Libro de la Salud, recuperados a partir de la estructura [tag="VM.*"][]\{o,1\}[lemma="signo|síntoma|indicio|señal|dolor|disfución|fiebre|picor|disn ea|tos"]

\subsection{Aparición y existencia de signos/síntomas}

El comienzo de una enfermedad suele venir marcado por la aparición de signos y síntomas. Para indicar que no existían antes, en español se utilizan verbos de existencia, bien de tipo general ('aparecer'), los que indican una fase inicial ('comenzar'), su prolongación en el tiempo ('persistir') o la duración de los síntomas ('durar'). Si se enfatiza la percepción de los síntomas, pero sin explicitar el sujeto que los percibe, se pueden seleccionar verbos de percepción como 'manifestarse' (Tabla 5).

Por otra parte, la enfermedad y los síntomas que la acompañan se conciben como un proceso. En consecuencia, los sintagmas nominales para expresar síntomas coocurren con verbos de proceso material de cambio, usados intransitivamente ('agravarse', 'aumentar', 'atenuarse', 'ceder', etc.) o bien con verbos de espaciodesplazamiento, dado que algunos síntomas como la fiebre se miden en relación con unos parámetros fisiológicos de normalidad, de ahí que estar por encima (o por debajo) de esos parámetros resulte negativo. Para los verbos de cambio, ADESSE señala que el sujeto tiene el rol semántico de 'agente', pero opinamos que, en relación con signos y síntomas, sería más adecuado hablar de un 'estímulo-agente'. 
Tabla 5. Patrones verbales para APARICIÓN Y EXISTENCIA DE SIGNOS/SÍNTOMAS.

\begin{tabular}{|c|c|c|c|c|}
\hline $\begin{array}{l}\text { Clase semántica del } \\
\text { verbo (subclase) }\end{array}$ & Val. & $\begin{array}{l}\text { Concepto para Sujeto } \\
\text { (rol semántico) }\end{array}$ & Verbos & $\begin{array}{l}\text { Concepto otros } \\
\text { argum. (rol sem.; } \\
\text { función) }\end{array}$ \\
\hline Existencial & 1 & $\begin{array}{l}\text { SIGNO Y SÍNTOMA } \\
\text { (existente) }\end{array}$ & $\begin{array}{l}\text { aparecer } \\
\text { predominar } \\
\text { reaparecer } \\
\text { sobrevenir }\end{array}$ & \\
\hline Mental (percepción) & 1 & $\begin{array}{l}\text { SiGNO Y SÍNTOMA } \\
\text { (percibido) }\end{array}$ & manifestarse & \\
\hline Existencial (fase) & 1 & $\begin{array}{l}\text { SIGNO Y SÍNTOMA } \\
\text { (proceso) }\end{array}$ & comenzar & \\
\hline Existencial (tiempo) & 1 & $\begin{array}{l}\text { SIGNO Y SÍNTOMA } \\
\text { (existente) }\end{array}$ & $\begin{array}{l}\text { perdurar } \\
\text { persistir }\end{array}$ & \\
\hline $\begin{array}{l}\text { Relacional (atribución- } \\
\text { propiedad-medida) }\end{array}$ & 2 & $\begin{array}{l}\text { SIGNO Y SÍNTOMA } \\
\text { (existente) }\end{array}$ & durar & $\begin{array}{l}\text { TiEMPO } \\
\text { (duración; CD) }\end{array}$ \\
\hline $\begin{array}{l}\text { Material (cambio- } \\
\text { modificación) }\end{array}$ & 1 & $\begin{array}{l}\text { SíNTOMA } \\
\text { (estímulo-agente) }\end{array}$ & $\begin{array}{l}\text { agravarse, } \\
\text { empeorar } \\
\text { agudizarse }\end{array}$ & \\
\hline $\begin{array}{l}\text { Material (cambio- } \\
\text { modificación) }\end{array}$ & 1 & $\begin{array}{l}\text { SIGNO Y SÍNTOMA } \\
\text { (estímulo-agente) }\end{array}$ & aumentar & \\
\hline $\begin{array}{l}\text { Material (espacio- } \\
\text { desplazamiento) }\end{array}$ & 2 & $\begin{array}{l}\text { SIGNO Y SÍNTOMA } \\
\text { (móvil) }\end{array}$ & subir & $\begin{array}{l}\text { (PACIENTE) } \\
\text { (afectado; CI) }\end{array}$ \\
\hline $\begin{array}{l}\text { Material (cambio- } \\
\text { modificación) }\end{array}$ & 1 & $\begin{array}{l}\text { SIGNO Y SÍNTOMA } \\
\text { (estímulo-agente) }\end{array}$ & $\begin{array}{l}\text { atenuarse } \\
\text { ceder } \\
\text { disminuir } \\
\text { remitir }\end{array}$ & \\
\hline Existencial (fase) & 1 & $\begin{array}{l}\text { SIGNO Y SÍNTOMA } \\
\text { (existente) }\end{array}$ & $\begin{array}{l}\text { cesar, } \\
\text { desaparecer }\end{array}$ & \\
\hline
\end{tabular}

También se muestran en la tabla verbos para cuantificar la intensidad de los síntomas, aumento ('aumentar', 'subir') o disminución ('atenuarse', 'ceder', 'disminuir', 'remitir'), así como verbos con una evaluación axiológica negativa: 'Los síntomas se agravan/empeoran'. En cualquier caso, al hablar de síntomas, normalmente las predicaciones van cargadas de una prosodia semántica negativa, aunque algunos indican una mayor negatividad: 'persistir', 'perdurar', 'agravarse' o 'empeorarse'. Finalmente, 'cesar' o 'desaparecer' indican que los síntomas ya no existen.

\subsection{Tener, percibir y sentir signos/síntomas}

En este marco, los síntomas se presentan en relación con el paciente, y los verbos se ordenan desde una menor a una mayor implicación y afectación del paciente. Es decir, a falta de contexto, la expresión 'el paciente presenta síntomas' resulta más neutra que 'nota síntomas', 'experimenta síntomas' o 'padece síntomas'. De igual manera, se puede indicar que el paciente no experimenta síntomas ('permanece asintomático') o que los 'tolera'. En las predicaciones de este marco no aparece implícitamente la figura de un profesional sanitario, algo que sí ocurrirá en el descrito en el apartado 3.5 . 
En la Tabla 6, los verbos del primer bloque enfatizan la manifestación y la percepción de los síntomas desde un punto de vista neutro, sin poner el foco en la experiencia y las molestias de estos para el paciente. Por ello, se utilizan: a) verbos relacionales donde el paciente 'tiene' unos síntomas, aunque obviamente, con esta colocación, el verbo no indica posesión, sino que adquiere el sentido de "sentir, sufrir o padecer [una sensación o enfermedad]" (ADESSE); b) verbos existenciales de fasetiempo ('desarrollar') que denotan que se va a iniciar un proceso en el paciente; y c) verbos de percepción ('mostrar', 'presentar', 'manifestar') cuyo sujeto es más bien iniciador que perceptor, dado que su cuerpo tiene unas características anormales que otras personas pueden percibir. Posteriormente, se presentan verbos de percepción y sensación propiamente dichos cuyo sujeto es una persona: la mayoría de percepción general ('detectar', 'notar', 'percibir'), alguno de percepción visual ('observar') y verbos de sensación ('sentir', 'sufrir', 'padecer'). 'Sufrir' y 'padecer' se refieren siempre en el corpus a síntomas, y nunca a signos. El verbo 'experimentar' puede entenderse como de sensación o de cambio. Después, hay verbos cuyo sujeto es SIGNOS/sínTOMAS, que causan una experiencia negativa ('aquejan', 'molestan', 'fastidian') al paciente o 'interfieren en su vida'.

Tabla 6. Patrones verbales para TENER, PERCIBIR Y SENTIR SIGNOS/SÍNTOMAS.

\begin{tabular}{|c|c|c|c|c|}
\hline $\begin{array}{l}\text { Clase semántica del } \\
\text { verbo (subclase) }\end{array}$ & Val. & $\begin{array}{l}\text { Concepto para } \\
\text { Sujeto (rol } \\
\text { semántico) }\end{array}$ & Verbos & $\begin{array}{l}\text { Concepto otros } \\
\text { argum. (rol; función) }\end{array}$ \\
\hline Relacional (posesión) & 2 & $\begin{array}{l}\text { PACIENTE } \\
\text { (poseedor) }\end{array}$ & tener & $\begin{array}{l}\text { SIGNO Y SÍNTOMA } \\
\text { (posesión; CD) }\end{array}$ \\
\hline $\begin{array}{l}\text { Existencial (fase- } \\
\text { tiempo, fase) }\end{array}$ & 2 & $\begin{array}{l}\text { PACIENTE } \\
\text { (iniciador) }\end{array}$ & desarrollar & $\begin{array}{l}\text { SIGNO Y SÍNTOMA } \\
\text { (proceso; CD) }\end{array}$ \\
\hline Mental (percepción) & 2 & $\begin{array}{l}\text { PACIENTE } \\
\text { PARTE DEL CUERPO } \\
\text { (iniciador) }\end{array}$ & $\begin{array}{l}\text { manifestar, } \\
\text { mostrar, presentar }\end{array}$ & $\begin{array}{l}\text { SIGNO Y SÍNTOMA } \\
\text { (percibido; CD) }\end{array}$ \\
\hline Mental (percepción) & 2 & $\begin{array}{l}\text { PACIENTE } \\
\text { (perceptor, experi- } \\
\text { mentador) }\end{array}$ & $\begin{array}{l}\text { detectar, notar, } \\
\text { observar, percibir, } \\
\text { sentir }\end{array}$ & $\begin{array}{l}\text { SIGNO Y SÍNTOMA } \\
\text { (percibido; CD) }\end{array}$ \\
\hline Mental (sensación) & 2 & $\begin{array}{l}\text { PACIENTE } \\
\text { (experimentador) }\end{array}$ & $\begin{array}{l}\text { experimentar, } \\
\text { padecer, sufrir }\end{array}$ & $\begin{array}{l}\text { SIGNO Y SÍNTOMA } \\
\text { (estímulo; CD) }\end{array}$ \\
\hline $\begin{array}{l}\text { Mental (cambio - } \\
\text { modificación) }\end{array}$ & 2 & $\begin{array}{l}\text { PACIENTE } \\
\text { (afectado) }\end{array}$ & experimentar & $\begin{array}{l}\text { SiGNO Y SÍNTOMA } \\
\text { (afectación; CD) }\end{array}$ \\
\hline Mental (sensación) & 2 & $\begin{array}{l}\text { SíNTOMA } \\
\text { (estímulo) }\end{array}$ & $\begin{array}{l}\text { aquejar, molestar, } \\
\text { fastidiar }\end{array}$ & $\begin{array}{l}\text { PACIENTE (experi- } \\
\text { mentador; CD) }\end{array}$ \\
\hline Existencial (fase) & 2 & $\begin{array}{l}\text { SíNTOMA } \\
\text { (iniciador) }\end{array}$ & interferir & $\begin{array}{l}\text { en VIDA DE PACIENTE } \\
\text { (proceso; c. rég. verbal) }\end{array}$ \\
\hline Mental (sensación) & 2 & $\begin{array}{l}\text { PACIENTE } \\
\text { (experimentador) }\end{array}$ & tolerar & SÍNTOMA (estímulo) \\
\hline $\begin{array}{l}\text { Material (espacio - } \\
\text { localización) }\end{array}$ & 2 & PACIENTE (móvil) & permanecer & $\begin{array}{l}\text { ASINTOMÁTICO / libre } \\
\text { de síntomas (manera; } \\
\text { compl. predicativo) }\end{array}$ \\
\hline
\end{tabular}




\subsection{Signos/síntomas relacionados con la enfermedad}

Hay verbos que establecen una conexión entre los signos y síntomas y las enfermedades (Tabla 7), pero esta relación no es causal, como la que mostramos en 3.4. En este marco predominan los verbos relacionales y los que indican relación en el tiempo que dura el proceso patológico ('precede', 'debuta con'). El verbo 'acompañar' evoca la metáfora de la enfermedad como camino que hay que recorrer.

Tabla 7. Patrones verbales para SIGNOS/SÍNTOMAS RELACIONADOS CON LA ENFERMEDAD (Argumentos).

\begin{tabular}{|l|l|l|l|l|}
\hline $\begin{array}{l}\text { Clase semántica del } \\
\text { verbo (subclase) }\end{array}$ & Val. & $\begin{array}{l}\text { Concepto para } \\
\text { Sujeto (rol sem.) }\end{array}$ & Verbos & $\begin{array}{c}\text { Concepto otros } \\
\text { argumentos (rol; función) }\end{array}$ \\
\hline $\begin{array}{l}\text { Material (espacio- } \\
\text { desplazamiento) }\end{array}$ & 2 & $\begin{array}{l}\text { SIGNO Y SínTOMA } \\
\text { (acompañante) }\end{array}$ & acompañar & $\begin{array}{l}\text { (a) ENFERMEDAD } \\
\text { (acompañado; CD /compl. } \\
\text { régimen verbal) }\end{array}$ \\
\hline $\begin{array}{l}\text { Relacional (atribución- } \\
\text { relación) }\end{array}$ & 2 & $\begin{array}{l}\text { SIGNO Y SínTOMA } \\
\text { (entidad) }\end{array}$ & $\begin{array}{l}\text { asociarse a } \\
\text { relacionarse con } \\
\text { cursar con } \\
\text { derivar de }\end{array}$ & $\begin{array}{l}\text { ENFERMEDAD } \\
\text { (entidad 2; compl. rég. } \\
\text { verbal) }\end{array}$ \\
\hline $\begin{array}{l}\text { Relacional (atribución- } \\
\text { relación) }\end{array}$ & 2 & $\begin{array}{l}\text { SIGNO Y SínTOMA } \\
\text { (entidad) }\end{array}$ & $\begin{array}{l}\text { llevar/traer } \\
\text { aparejado }\end{array}$ & $\begin{array}{l}\text { ENFERMEDAD } \\
\text { (entidad 2; CD) }\end{array}$ \\
\hline $\begin{array}{l}\text { Material (espacio- } \\
\text { temporal) }\end{array}$ & 2 & $\begin{array}{l}\text { SIGNO Y SÍNTOMA } \\
\text { (móvil 1) }\end{array}$ & preceder & $\begin{array}{l}\text { ENFERMEDAD } \\
\text { (móvil 2; CD) }\end{array}$ \\
\hline $\begin{array}{l}\text { Existencial (fase) y } \\
\text { Material (actividad) }\end{array}$ & 2 & $\begin{array}{l}\text { ENFERMEDAD } \\
\text { (iniciador) }\end{array}$ & debutar con & $\begin{array}{l}\text { SIGNO/SÍNTOMA } \\
\text { (coocurrente; c.rég.verbal) }\end{array}$ \\
\hline
\end{tabular}

También encontramos verbos de percepción usados de forma reflexiva con un único argumento y con SigNOS/SíNTOMAS actuando como satélite, en concreto, como complemento circunstancial de modo (Tabla 8).

Tabla 8. Patrones para SIGNOS/SÍNTOMAS RELACIONADOS CON LA ENFERMEDAD (Argumentos y satélites).

\begin{tabular}{|c|c|c|c|c|}
\hline Mental (percepción) & 1 & $\begin{array}{c}\text { ENFERMEDAD } \\
\text { (percibido) }\end{array}$ & manifestarse & $\begin{array}{c}\text { como SIGNO/SÍNTOMA } \\
\text { (percibido2; CC modo) }\end{array}$ \\
\hline
\end{tabular}

\subsection{La enfermedad causa signos/síntomas}

Este patrón de conocimiento se comunica con verbos de existencia y procesos materiales de cambio (Tabla 9). La enfermedad inicia un fenómeno que no existía en el cuerpo, y esto se expresa con verbos como 'causar', 'generar', 'ocasionar' o 'provocar' ("hacer ocurrir como reacción o respuesta"). El verbo 'desencadenar' indica que los signos y síntomas inician un proceso que conlleva efectos negativos. 
Tabla 9. Patrones verbales para LA ENFERMEDAD CAUSA SIGNOS/SÍNTOMAS.

\begin{tabular}{|l|l|l|l|l|}
\hline $\begin{array}{l}\text { Existencial } \\
\text { (existencia) }\end{array}$ & 2 & $\begin{array}{l}\text { ENFERMEDAD } \\
\text { (iniciador) }\end{array}$ & $\begin{array}{l}\text { causar, generar, } \\
\text { ocasionar, provocar }\end{array}$ & $\begin{array}{l}\text { SIGNO Y SíNTOMA } \\
\text { (existente; CD) }\end{array}$ \\
\hline Existencial (fase) & 2 & $\begin{array}{l}\text { ENFERMEDAD } \\
\text { (iniciador) }\end{array}$ & desencadenar & $\begin{array}{l}\text { SIGNO Y SÍNTOMA (entidad- } \\
\text { proceso; CD) }\end{array}$ \\
\hline $\begin{array}{l}\text { Material (cambio, } \\
\text { creación) }\end{array}$ & 2 & $\begin{array}{l}\text { ENFERMEDAD } \\
\text { (creador) }\end{array}$ & producir & $\begin{array}{l}\text { SIGNO Y SÍNTOMA } \\
\text { (creación; CD) }\end{array}$ \\
\hline
\end{tabular}

\subsection{Signos y síntomas en el diagnóstico de la enfermedad}

Otro contexto sería el de la atención médica; en concreto, cómo se diagnostica la enfermedad (apartado 3.5), cómo se previenen y se controlan los síntomas (3.6) y cómo se alivia la enfermedad (3.7). En la consulta médica, tal y como se recoge en el apartado de anamnesis de las historias clínicas, el paciente refiere al médico el motivo y los síntomas que lo han llevado a consulta. A continuación el médico le pregunta sobre sus hábitos de vida y antecedentes personales (intervenciones quirúrgicas previas, medicación...) y familiares en relación con enfermedades. El objetivo de estas preguntas y de la exploración física que realizará el profesional sanitario es establecer un diagnóstico. Durante la exploración y con la ayuda de pruebas diagnósticas, el facultativo hallará signos, y el paciente puede experimentar y expresar sus síntomas con un lenguaje verbal y no verbal.

Por este motivo, los textos escritos muestran (Tabla 10): a) verbos de comunicación ('describir', 'manifestar', 'referir') y cambio ('experimentar') cuyo sujeto es el PACIENTE que acude a consulta; b) verbos de percepción ('advertir', 'apreciar', 'detectar', 'hallar', etc.) cuyo sujeto es el PROFESIONAL SANITARIO; c) verbos para relacionar los SIGNOS Y SÍNTOMAS con una enfermedad concreta ('representar', 'caracterizar'....) o para indicar que no existe tal relación ('descartar'); d) verbos con un uso figurado cuyo sujeto es un SIGNO/SÍNTOMA 'personificado' con rol semántico de alertador, comunicador o iniciador que participa en predicaciones de comunicación, percepción o conocimiento. Como ejemplo de esto último, encontramos síntomas que 'alertan', 'delatan', 'señalan', 'sugieren', 'evidencian' o 'ayudan a diagnosticar' una enfermedad; e) verbos de percepción como 'distinguir', que lleva tres argumentos. 
Tabla 1o. Patrones verbales para SIGNOS/SÍNTOMAS EN EL DIAGNÓSTICO DE LA ENFERMEDAD.

\begin{tabular}{|c|c|c|c|c|}
\hline $\begin{array}{l}\text { Verbal } \\
\text { (comunicación) }\end{array}$ & 2 & $\begin{array}{l}\text { PACIENTE } \\
\text { (comunicador) }\end{array}$ & $\begin{array}{l}\text { describir, manifestar, } \\
\text { referir }\end{array}$ & $\begin{array}{l}\begin{array}{l}\text { SIGNO Y SÍNTOMA } \\
\text { (mensaje; } \mathrm{CD})\end{array} \\
\end{array}$ \\
\hline $\begin{array}{l}\text { Mental (cambio - } \\
\text { modificación) }\end{array}$ & 2 & $\begin{array}{l}\text { PACIENTE } \\
\text { (afectado) }\end{array}$ & experimentar & $\begin{array}{l}\text { SIGNO Y SÍNTOMA } \\
\text { (afectación; CD) }\end{array}$ \\
\hline Mental (percepción) & 2 & $\begin{array}{l}\text { PROFESIONAL } \\
\text { SANITARIO } \\
\text { (perceptor) }\end{array}$ & $\begin{array}{l}\text { advertir, apreciar, captar, } \\
\text { detectar, hallar, ver, } \\
\text { encontrar, percibir, } \\
\text { identificar, observar }\end{array}$ & $\begin{array}{l}\text { ENFERMEDAD/ } \\
\text { PARÁMETRO ANORMAL } \\
\text { (percibido; CD) }\end{array}$ \\
\hline $\begin{array}{l}\text { Relacional } \\
\text { (atribución, } \\
\text { relación) }\end{array}$ & 2 & $\begin{array}{l}\text { SIGNO Y } \\
\text { SÍNTOMA } \\
\text { (entidad) } \\
\end{array}$ & $\begin{array}{l}\text { caracterizar /ser } \\
\text { característico de, } \\
\text { representar, denotar }\end{array}$ & $\begin{array}{l}\text { ENFERMEDAD/ } \\
\text { PARÁM. ANORMAL } \\
\text { (entidad2; CD) } \\
\end{array}$ \\
\hline $\begin{array}{l}\text { Verbal } \\
\text { (comunicación) }\end{array}$ & 2 & $\begin{array}{l}\text { SIGNO Y } \\
\text { SÍNTOMA } \\
\text { (comunicador) }\end{array}$ & $\begin{array}{l}\text { alertar, señalar, sugerir } \\
\text { / ser sugerente de }\end{array}$ & $\begin{array}{l}\text { de (presencia de) } \\
\text { ENFERMEDAD (asunto; } \\
\text { compl. rég. verbal) }\end{array}$ \\
\hline $\begin{array}{l}\text { Material (espacio- } \\
\text { orientación) }\end{array}$ & 2 & $\begin{array}{l}\text { SIGNO Y } \\
\text { SÍNTOMA } \\
\text { (iniciador) }\end{array}$ & apuntar & $\begin{array}{l}\text { a (la presencia de) } \\
\text { ENFERMEDAD } \\
\text { (orientación; compl. } \\
\text { circunst. lugar) } \\
\end{array}$ \\
\hline Mental (percepción) & 2 & $\begin{array}{l}\text { SiGNO/SÍNTOMA } \\
\text { (iniciador) }\end{array}$ & $\begin{array}{l}\text { delatar, } \\
\text { indicar, reflejar }\end{array}$ & $\begin{array}{l}\text { ENFERMEDAD } \\
\text { (percibido; CD) }\end{array}$ \\
\hline $\begin{array}{l}\text { Mental (cognición- } \\
\text { conocimiento) }\end{array}$ & 2 & $\begin{array}{l}\text { SiGNO/SÍNTOMA } \\
\text { (iniciador) }\end{array}$ & $\begin{array}{l}\text { evidenciar, ayudar a } \\
\text { diagnosticar }\end{array}$ & $\begin{array}{l}\text { ENFERMEDAD } \\
\text { (contenido; CD) }\end{array}$ \\
\hline $\begin{array}{l}\text { Relacional } \\
\text { (atribución,relación) }\end{array}$ & 2 & $\begin{array}{l}\text { SIGNO/SÍNTOMA } \\
\text { (entidad) }\end{array}$ & descartar & $\begin{array}{l}\text { ENFERMEDAD } \\
\text { (entidad2; CD) }\end{array}$ \\
\hline Mental (percepción) & 3 & $\begin{array}{l}\text { SIGNO Y } \\
\text { SÍNTOMA } \\
\text { (perceptor) }\end{array}$ & distinguir & $\begin{array}{l}\text { Arg. 2: ENFERMEDAD } \\
\text { (percibido; c. rég. verbal) } \\
\text { Arg. 3: ENFERMEDAD } \\
\text { (referencia; c. rég. verbal) }\end{array}$ \\
\hline
\end{tabular}

\subsection{Prevención y control de signos y síntomas}

Los verbos de este marco (Tabla 11) aluden a que ciertos HÁBITOS SALUDABLES y TRATAMIENTOS previenen y evitan la aparición de signos y síntomas, o bien mantienen bajo control a los existentes. Los profesionales de la salud (y por defecto, los pacientes) vigilarán los signos y síntomas, de ahí que también se utilicen verbos de percepción. 
Tabla 11. Patrones para PREVENCIÓN Y CONTROL DE SIGNOS Y SÍNTOMAS.

\begin{tabular}{|l|l|l|l|l|}
\hline $\begin{array}{l}\text { Modulación } \\
\text { (disposición) }\end{array}$ & $\begin{array}{l}\text { HÁBITO SALUDABLE, } \\
\text { TRATAMIENTO (actor) }\end{array}$ & evitar & $\begin{array}{l}\text { SIGNO Y SÍNTOMA } \\
\text { (acción; CD) }\end{array}$ \\
\hline $\begin{array}{l}\text { Material (otros } \\
\text { hechos-actividad) }\end{array}$ & 2 & $\begin{array}{l}\text { HÁBITO SALUDABLE, } \\
\text { TRATAMIENTO (actor) }\end{array}$ & prevenir & $\begin{array}{l}\text { SIGNO Y SÍNTOMA } \\
\text { (amenaza; CD) }\end{array}$ \\
\hline $\begin{array}{l}\text { Material (otros } \\
\text { hechos-control) }\end{array}$ & 2 & $\begin{array}{l}\text { TRATAMIENTO, } \\
\text { HÁBITO SALUDABLE } \\
\text { (controlador) }\end{array}$ & $\begin{array}{l}\text { controlar } \\
\text { mantener a raya }\end{array}$ & $\begin{array}{l}\text { SIGNO Y SÍNTOMA } \\
\text { (controlado; CD) }\end{array}$ \\
\hline Mental (percepción) & 2 & $\begin{array}{l}\text { PROFESIONAL } \\
\text { SANITARIO (perceptor) }\end{array}$ & $\begin{array}{l}\text { monitorizar } \\
\text { seguir la evolución de } \\
\text { vigilar }\end{array}$ & $\begin{array}{l}\text { SIGNO Y SíNTOMA } \\
\text { (percibido; CD) }\end{array}$ \\
\hline
\end{tabular}

\subsection{Alivio de los síntomas (tratamiento sintomático)}

Finalmente, también en el marco de la atención sanitaria, hallamos predicaciones de tipo material para indicar el tratamiento de los síntomas. Son verbos transitivos de cambio-modificación ('aliviar') o de cambio-destrucción ('eliminar', 'suprimir'). Como la enfermedad y los síntomas son un proceso, hay un uso metafórico de verbos de localización para expresar que se ‘detienen' los síntomas.

Tabla 12. Patrones verbales para ALIVIO DE LOS SÍNTOMAS (TRATAMIENTO SINTOMÁTICO).

\begin{tabular}{|l|l|l|l|l|}
\hline $\begin{array}{l}\text { Material (cambio - } \\
\text { modificación) }\end{array}$ & 2 & $\begin{array}{l}\text { TRATAMIENTO, } \\
\text { HÁBITO SALUDABLE } \\
\text { (agente) }\end{array}$ & $\begin{array}{l}\text { aliviar, apaciguar, aplacar, } \\
\text { atenuar, calmar, frenar, } \\
\text { mejorar, mitigar, paliar, } \\
\text { tratar }\end{array}$ & $\begin{array}{l}\text { SÍNTOMA } \\
\text { (afectado; CD) }\end{array}$ \\
\hline $\begin{array}{l}\text { Material (espacio- } \\
\text { localización) }\end{array}$ & 2 & $\begin{array}{l}\text { TRATAMIENTO, } \\
\text { HÁBITO SALUDABLE } \\
\text { (iniciador) }\end{array}$ & detener & $\begin{array}{l}\text { SÍNTOMA } \\
\text { (móvil; CD) }\end{array}$ \\
\hline $\begin{array}{l}\text { Material (cambio - } \\
\text { destrucción) }\end{array}$ & 2 & $\begin{array}{l}\text { TRATAMIENTO, } \\
\text { HÁBITO SALUDABLE } \\
\text { (destructor) }\end{array}$ & eliminar, suprimir & $\begin{array}{l}\text { SIGNO Y SíNTOMA } \\
\text { (destruido; CD) }\end{array}$ \\
\hline
\end{tabular}

\subsection{Recapitulación de resultados}

Se han identificado 23 subclases de verbos, pertenecientes a las clases MATERIAL, MENTAL, EXISTENCIAL, RELACIONAL y VERBAL, por orden de importancia. Estas clases de ADESSE se corresponden con las de CHANGE, ACTION, PERCEPTION, COGNITION, FEELING, EXISTENCE y SPEECH de la Gramática Léxica (Faber \& Mairal, 1999). Se detallan los marcos predicativos encontrados y sus subtipos en la Figura 5. 


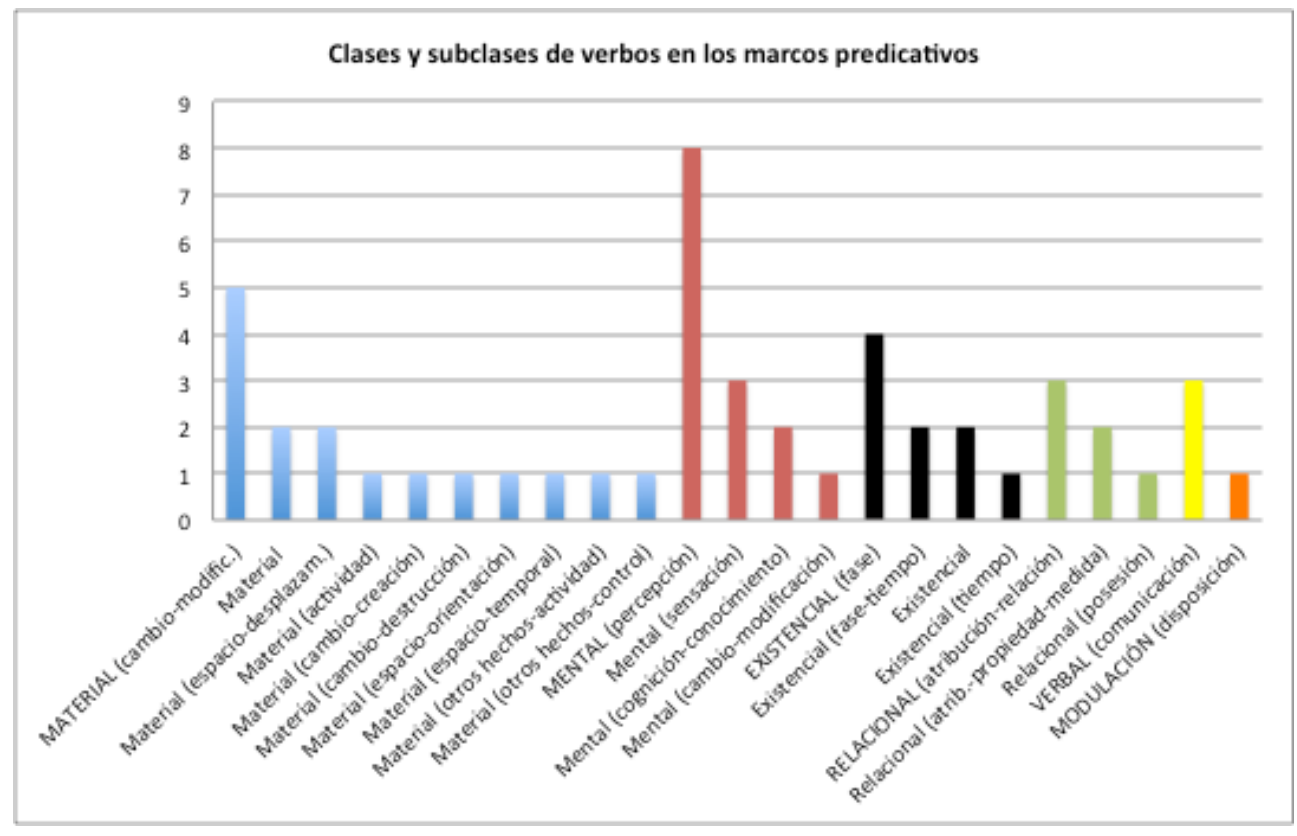

Figura 5. Clases semánticas de los marcos predicativos analizados.

Aunque este estudio no es cuantitativo, puesto que se ha priorizado la clasificación semántica y la descripción de los patrones combinatorios, sí podemos señalar que las subclases de verbos predominantes son MENTAL (PERCEPCIÓN), instanciada en verbos como 'apreciar', 'detectar', 'hallar', 'percibir', etc. y MATERIAL (CAMBIOMODIFICACIÓN), con verbos tales como 'agravarse', 'aumentar', 'atenuarse' o 'ceder'. Los argumentos de estas predicaciones son los conceptos SIGNO Y SÍNTOMA, PACIENTE, PARTE DEL CUERPO, ASINTOMÁTICO/LIBRE DE SÍNTOMAS, VIDA DE PACIENTE, ENFERMEDAD, PARÁMETro ANORMAL, ProfESIONAL SANitArio, HÁbito SALUdABle y Tratamiento. Centrándonos en las lexicalizaciones de SIGNO Y SÍNTOMA, PACIENTE y ENFERMEDAD, que son los más frecuentes en los marcos predicativos identificados, en línea con el marco propuesto por FrameNet (Figura 1), estos conceptos ocuparían las posiciones de los argumentos que se especifican en la Tabla 13.

Tabla 13. Posiciones argumentales con respecto a los verbos.

\begin{tabular}{|l|c|c|c|}
\hline & Argumento 1 & Argumento 2 & Argumento 3 \\
\hline SIGNO Y SÍNTOMA & 23 & 14 & \\
\hline PACIENTE & 10 & 3 & \\
\hline ENFERMEDAD & 5 & 12 & 1 \\
\hline
\end{tabular}




\section{CONCLUSIONES}

Este artículo se centra en los verbos léxicos que suelen aparecer conjuntamente con expresiones que denotan SIGNO Y SÍNTOMA en textos sobre medicina. Tras definir los conceptos SIGNO y SÍNTOMA en un contexto médico se ha analizado desde el punto de vista semántico y sintáctico cómo sus lexicalizaciones encajan en marcos predicativos que gravitan en torno a un verbo. A partir de las nociones de 'escena', 'marco', 'patrón verbal', 'valencia verbal' y ‘rol semántico' se ha estudiado el potencial combinatorio de los verbos y de sus argumentos en la construcción de significado.

Consideramos que la metodología diseñada para recuperar verbos prototípicos y patrones lingüísticos de forma semiautomática ha sido adecuada para plasmar el mayor número de marcos predicativos y significados en torno al concepto SIGNO Y SÍNTOMA. Se han analizado corpus etiquetados morfológicamente con Sketch Engine desde un prisma más cualitativo que cuantitativo porque sería inviable sostener que el corpus es representativo de los textos médicos publicados en lengua española. En cualquier caso, esperamos que la representación de estos marcos predicativos en español pueda beneficiar a científicos, redactores técnicos y traductores que comunican avances científicos en lengua española, y por ende, al público lego.

\section{REFERENCIAS BIBLIOGRÁFICAS}

Albertuz, F. (2007). Sintaxis, semántica y clases de verbos: Clasificación verbal en el proyecto ADESSE. En P. Cano López (Coord.), Actas del VI Congreso de Lingüistica General (pp. 2015-2030). Madrid: Arco Libros.

Barsalou, L. W. (2008). Situating concepts. En P. Robbins \& M. Aydede (Eds.), Cambridge Handbook of Situated Cognition (pp. 236-263). Nueva York: Cambridge University Press.

Barsalou, L. W. (1992). Frames, concepts, and conceptual fields. En A. Lehrer \& E.F. Kittay (Eds.), Frames, Fields and Contrasts: New Essays in Semantic and Lexical Organization (pp. 21-74). Hillsdale, NJ: Lawrence Erlbaum Associates.

Bosque, I. \& Demonte, V. (Coords.) (1999). Gramática descriptiva de la lengua española. Madrid: Real Academia Española/Espasa Calpe.

Buendía, M. (2013). Phraseology in specialized language and its representation in environmental knowledge resources. Tesis doctoral, Universidad de Granada, España.

Buendía, M., León, P. \& Sánchez, B. (2016). Categorías semánticas para describir estructuras argumentales en un ámbito de especialidad. En D. Trotter, A. Bozzi \& C. Fairon (Eds.), Actes du XXVIIe Congrès international de linguistique et de philologie romanes (pp. 65-78). Nancy: ATILF. 
Cademártori, Y., Parodi, G. \& Venegas, R. (2006). El discurso escrito y especializado: Caracterización y funciones de las nominalizaciones en los manuales técnicos. Literatura y Lingüistica, 17, 243-265.

Claros, G. M. (2016). Cómo traducir y redactar textos cientificos en español. Reglas, ideas y consejos. Cuadernos de la Fundación Dr. Antonio Esteve No 39. Barcelona: Fundación Dr. Antonio Esteve.

Cortés Gabaudan, F. (Coord.). (2007). Dicciomed: Diccionario médico-biológico, histórico y etimológico. Salamanca: Universidad de Salamanca. [en línea]. Disponible en: http://dicciomed.eusal.es/.

Demonte, V. (1990). Transitividad, intransitividad y papeles temáticos. En V. Demonte \& B. Garza (Comps.), Estudios de Lingüística de España y México (pp. 115-150). Ciudad de México: El Colegio de México-UNAM.

Dik, S. C. (1989). The theory of functional grammar. Part I: The Structure of the Clause. Dordrecht: Foris Publications.

Dowty, D. (1991). Thematic proto-roles and argument selection. Language, 67(3), 547619.

Escandell, V. (2004). Fundamentos de lingüistica composicional. Barcelona: Ariel.

Faber, P. (1999). Conceptual analysis and knowledge acquisition in scientific translation. Terminologie et traduction, 2, 97-123.

Faber, P. (Ed.) (2012). A cognitive linguistics view of terminology and specialized language. Berlín, Boston: De Gruyter Mouton.

Faber, P. \& Mairal, R. (1999). Constructing a lexicon of English verbs. Berlín: Mouton de Gruyter.

Fillmore, C. (1977). Scenes-and-frames semantics. En A. Zampolli (Ed.), Linguistic Structures Processing (pp. 55-81). Ámsterdam: North Holland.

Fillmore, C. \& Atkins, B. T. (1992). Towards a frame-based lexicon: The semantics of RISK and its neighbors. En A. Lehrer \& E. F. Kittay (Eds.), Frames, Fields and Contrasts: New Essays in Semantic and Lexical Organization (pp. 75-102). Hillsdale, NJ: Lawrence Erlbaum Associates.

García-Miguel, J. M. (2005). Verbos aspectuales en español. La interacción de significado verbal y significado construccional. En G. M. Rio-Torto, O. Figueiredo \& F. Silva (Coords.), Estudos em Homenagem do Professor Doutor Mário Vilela (pp. 405-418). Oporto: Faculdade de Letras da Universidade do Porto. 
García Palacios, J. \& Humbley, J. (2012). En torno a la dependencia terminológica. Hermeneus, 14, 133-165.

Halliday, M.A.K. (2004). The language of science. Londres/Nueva York: Continuum.

Halliday, M.A.K. \& Matthiessen, C.M.I.M. (2004). An introduction to functional grammar. Londres: Hodder Education.

Jiménez, M. A. \& Tercedor, M. (2017). Lexical variation, register and explicitation in medical translation: A comparable corpus study of medical terminology in US websites translated into Spanish. Translation and Interpreting Studies, 12(3), 405426.

L’Homme, M. C. (1998). Définition du statut du verbe en langue de spécialité et sa description lexicographique. Cabiers de lexicologie, 73(2), 61-84.

L'Homme, M. C. (2003). Capturing the lexical structure in special subject fields with verbs and verbal derivatives: A model for specialized lexicography. International Journal of Lexicography, 16(4), 403-422.

Lehrer, A. \& Kittay, E. F. (1992). Frames, fields and contrasts: New essays in semantic and lexical organization. Hillsdale, NJ: Lawrence Erlbaum Associates.

Lezcano, E. (1994-1995). Una aproximación a la gramática de valencias. Lenguaje y textos, 6-7, 161-174.

Lexical Computing Ltd. (s. f.). Sketch Engine [en línea]. Disponible en: http://www.sketchengine.co.uk/

López Rodríguez, C. I. (2007). Understanding scientific communication through the extraction of the conceptual and rhetorical information codified by verbs. Terminology, 13(1), 61-84.

López Rodríguez, C. I. (2016). Explicitness of specialized terminology in popular science: An English into Spanish corpus-based study. En G. Corpas Pastor \& M. Seghiri (Eds.), Corpus-based Approaches to Translation and Interpreting: from theory to applications (pp. 79-104). Frankfurt: Peter Lang.

Lorente Casafont, M. (2002). Verbos y discurso especializado. Estudios de lingüística española (ELiEs) 16 [en línea]. Disponible en: http:// elies.rediris.es/elies16/Lorente.html

Navarro, F. A. (1997). Traducción y lenguaje en medicina. Cuadernos de la Fundación Dr. Antonio Esteve. Barcelona: Fundación Dr. Antonio Esteve. 
Onco'Term (2002). OncoTerm: Sistema bilingüe de información y recursos oncológicos len línea]. Disponible en: http://www.ugr.es/ oncoterm/oncodesc.htm

Real Academia Española y Asociación de Academias de la Lengua Española (2009). Nueva gramática de la lengua española. Madrid: Espasa.

Reisinger, D., Rudinger, R., Ferraro, F., Harman, C., Rawlins, K. \& Van Durme, B. (2015). Semantic proto-roles. Transactions of the Association for Computational Linguistics, 3, 475-488.

Rodríguez Medina, M. J. (2003). La traducción de la morfosintaxis (inglés-español): Teoría y práctica. Las Palmas de Gran Canaria: Universidad de las Palmas de Gran Canaria.

Rosch, E. \& Mervis, C. M. (1975). Family resemblances: Studies in the internal structure of categories. Cognitive Psychology, 8, 382-439.

Tercedor, M., López, C. I. \& Prieto, J. A. (2014). También los pacientes hacen terminología: Retos del proyecto Varimed.Panace@, 15(39), 95-102.

Tesnière, L. (1959). Éléments de syntaxe structural. París: Klincksieck.

Van Valin Jr, R. D. (2004). Semantic macroroles in role and reference grammar. En R. Kailuweit \& M. Hummel (Eds.), Semantische Rolen (pp. 62-82). Tubinga: Nar [en línea]. Disponible en: http://www.acsu.buffalo.edu/ rrgpage/rrg/vanvalin_papers/SemMRsRRG. pdf

Vendler, Z. (1967). Linguistics in Philosophy. Ithaca, NY: Cornell University Press.

\section{NOTAS}

1 Esta investigación se enmarca en el proyecto CombiMed: Léxico Combinatorio en Medicina: Cognición, texto y contexto (FFI2014-51899-R), en el que se analizan combinaciones léxicas y variantes terminológicas en medicina para su representación en un diccionario médico inglésespañol.

${ }^{2}$ García Palacios y Humbley (2012: 21) definen dependencia terminológica como "la relación de subordinación que se establece en la terminología de un dominio entre dos lenguas, una de las cuales es la exportadora de terminología y otra la terminológicamente dependiente de la primera".

${ }^{3}$ Según Dowty (1991: 572), las propiedades que contribuyen a que un argumento tenga rol de protoagente son: "a. volitional involvement in the event or state; b. sent[i]ence (and/or 
perception); c. causing an event or change of state in another participant; d. movement (relative to the position of another participant); (e. exists independently of the event named by the verb)". Las que contribuyen al rol de proto-paciente son: "a. undergoes change of state; b. incremental theme; c. causally affected by another participant; d. stationary relative to movement of another participant; (e. does not exist independently of the event, or not at all)". Por ejemplo, un experimentador cumpliría las propiedades de proto-agente b y c, y la propiedad c de proto-paciente (Reisinger et al., 2015).

${ }^{4}$ Esta primera superclase de verbos transitivos incluye verbos de acción resultativa, carácter causal, modificación/ afectación, objeto de lugar, posesión, influencia y comunicación verbal (Bosque \& Demonte, 1999).

5 Los verbos de actividad cognitiva pueden expresan los significados de percepción (percepción física, percepción intelectual, actividad para lograr la percepción en uno mismo, actitud proposicional), voluntad/sentimiento (voluntad, sensación y necesidad/merecimiento) y afección no causativo (afecto, sentimiento o gusto).

6 El aspecto léxico se denomina también 'modo de acción', 'cualidad de la acción' o 'accionalidad'; en inglés, State of Affairs, y en alemán, Aktionsart.

${ }^{7}$ Las clases y subclases propuestas por ADESSE, como afirma Albertuz (2007), parten de las clasificaciones del léxico verbal de Halliday, Faber y Mairal (1999), FrameNet y WordNet.

8 [en línea]. Disponibles en: https://talp-upc.gitbooks.io/freeling-usermanual/content/tagsets/tagset-es.html

9 En la sección Los sintomas más frecuentes: https://www.onmeda.es/sintomas/sintomas_frecuentes.html 